\title{
ANÁLISE DO RISCO RUÍDO EM INDÚSTRIA DE CONFECÇÃO DE ROUPA
}

\author{
Noise in the Clothing Industry
}

\author{
Daniela Dalapicula Barcelos(1) , Soraya Gama de Ataíde (2)
}

\begin{abstract}
RESUMO
Objetivo: verificar a presença do ruído em indústria de confecção de roupas, visto que este risco é pouco difundido nas pesquisas relacionadas a este ambiente de trabalho. Métodos: a empresa escolhida foi uma fábrica de confecção de roupa localizada em Colatina no Espírito Santo/Brasil. Foram analisados os dois setores com maior risco ruído na empresa, após a exclusão dos funcionários com menos de cinco anos de trabalho neste local, totalizamos uma amostra de seis funcionários. Os trabalhadores selecionados responderam questionário sobre informações e sintomas auditivos e posteriormente, foram analisadas as audiometrias realizadas nos últimos cinco anos. Resultados: por meio de medições realizadas nos setores analisados, constatou-se produção de ruído de 83,5 a $97,8 \mathrm{~dB}(\mathrm{~A})$. Após observar o histórico das audiometrias, obteve-se $83 \%$ dos trabalhadores, destes setores, sem perda auditiva, $16 \%$ com perda ocupacional, sendo classificada como estável. Os dados levantados no questionário revelaram que $33 \%$ dos trabalhadores sentem-se irritados quando expostos a sons elevados, $50 \%$ sentem-se estressados após a jornada de trabalho, e nenhum trabaIhador relatou queixa de zumbido, insônia ou dificuldade em entender as pessoas. Conclusão: este ambiente de trabalho apresenta risco ruído, uma vez constatados os níveis de pressão sonora no qual os trabalhadores são expostos durante a jornada de trabalho, bem como a presença de perda auditiva ocupacional, mesmo em menor escala - atribuído ao tempo mínimo de cinco anos de serviços prestados utilizado na pesquisa.
\end{abstract}

DESCRITORES: Perda Auditiva; Perda Auditiva Provocada por Ruído; Riscos Ocupacionais; Vestuário

\section{INTRODUÇÃO}

A audição é um dos sentidos mais nobres, sua principal função está ligada à aquisição e ao desenvolvimento da linguagem oral, essencial nas relações interpessoais e com o meio ambiente 1. Devido a essa importância, é que estudiosos buscam cada vez mais formas de prevenir a ocorrência de perdas auditivas, em especial as causadas pelo ruído.

"O ruído ameaça a audição, a saúde, a aprendizagem e o comportamento", afirma Nancy Nadler, porta-voz do Center for Hearing and Communication $(\mathrm{CHC})$, responsável pela instituição

\footnotetext{
(1) Universidade Vila Velha - UVV, Vitória, ES, Brasil.

(2) Curso de Especialização em Audiologia do CEFAC, Vitória, ES, Brasil.

Conflito de interesses: inexistente
}

do Dia Internacional da Conscientização sobre o Ruído, afetando o ser humano nos planos físico, psicológico e social ${ }^{2}$. Em alta intensidade e com exposição continuada, o ruído pode causar alterações estruturais na orelha interna, que determinam a ocorrência da Perda Auditiva Induzida por Ruído (PAIR), e é o motivo de agravo mais frequente à saúde dos trabalhadores ${ }^{3}$, estando presente em diversos ramos de atividade ${ }^{4}$, como por exemplo, em indústrias, confecções, obras de construção civil, metalúrgicas, gráficas, ateliês de costura, entre outros ambientes de trabalho ${ }^{5}$.

A indústria do vestuário no país surgiu a partir do processo de industrialização nacional com a produção têxtil. Com a evolução da indústria têxtil, ocorreu a modernização do setor de confecção, que hoje possui vinte e um segmentos distintos de artigos de vestuário e acessórios, de acordo com a classificação da ABRAVEST - Associação 
Brasileira do Vestuário ${ }^{6}$. Este é um dos setores que mais cedo se desenvolveu no país, por exigir pouco nível tecnológico e pequeno investimento de capital, em muitas regiões, assim como ocorreu no início da industrialização do Brasil, essa indústria é a precursora do processo de industrialização.

Com os esforços em aumentar a quantidade de produção e manter os produtos em competitividade no mercado, as empresas investem e modernizam cada vez mais rápido os seus maquinários. A grande necessidade de mão-de-obra diversificada no setor, devida à variedade de etapas produtivas no setor, tais como: almoxarifado de tecidos e aviamentos, criação, modelagem, enfesto, corte, costura, artesanato, lavanderia, passadoria, acabamento, etiquetagem, embalagem, inspeção final, e expedição ${ }^{6}$; atrai a população que busca por um serviço remunerado.

Este nicho de mercado que vem crescendo constantemente, é pouco explorado nas pesquisas científicas quanto as condições de trabalho e a saúde do trabalhador. Há pouca explanação sobre este ambiente no âmbito da fonoaudiologia, e se ele apresenta algum risco, em especial, a audição do empregado.

Devido a esse questionamento, o objetivo deste estudo é verificar a presença do ruído em indústria de confecção de roupas, visto que este risco é pouco difundido nas pesquisas relacionadas a este ambiente de trabalho.

\section{MÉTODOS}

A pesquisa, do tipo retrospectiva e documental, foi realizada em uma empresa de confecção de roupa localizada em Colatina-ES/Brasil.

A indústria escolhida possui um universo total de 368 funcionários. Por meio do Programa de Prevenção de Riscos Ambientais (PPRA) fornecido pelos mesmos, foram analisadas as medições de ruído em cada setor, e assim, levantados os dois setores de maior risco ruído, identificados como Passadoria e Área do USED. Atualmente o número total de funcionários que ocupam esses setores é 6 e 4 funcionários respectivamente, totalizando 10 trabalhadores. Após a aplicação dos critérios de exclusão, foram selecionados somente 6 trabalhadores para participar da pesquisa (4 trabalhadores da Passadoria e 2 trabalhadores do Used).

Os critérios de exclusão foram: funcionários com menos de cinco anos de serviços prestados a empresa participante; os trabalhadores de outros setores com menor intensidade ou nenhum risco ruído e os trabalhadores que não quiseram participar voluntariamente da pesquisa. Com os sujeitos selecionados, analisou-se as audiometrias realizadas desde o exame admissional até o exame atual (2011), não podendo, portanto, ter menos do que cinco exames para cada trabalhador (pelo menos um exame referente a cada ano), disponíveis nos prontuários médicos arquivados no setor responsável por essa função. As audiometrias foram analisadas quanto à normalidade e presença de perda auditiva, sendo estas subdivididas em ocupacionais e não-ocupacionais. As perdas auditivas ocupacionais encontradas foram analisadas quanto à estabilidade, agravamento ou desencadeamento.

Os funcionários selecionados, responderam em um único dia e individualmente, questionário aprovado pelo comitê de ética - protocolo 071/11 (Figura 1) do tipo fechado sobre informações e sintomas auditivos contendo quatro questões, elaborado pela pesquisadora com base nas descrições sobre sintomas em casos de PAIR encontrados na literatura.

Com os questionários respondidos, os mesmos foram recolhidos e os trabalhadores dispensados. As respostas obtidas por meio do questionário e da análise das audiometrias foram transformadas em percentuais e apresentadas neste trabalho por meio de gráficos.

\section{RESULTADOS}

\section{Descrição do campo de pesquisa: Síntese da infra-estrutura da empresa selecionada}

A empresa analisada está localizada no município de Colatina, no estado do Espírito Santo, e atua na confecção de roupas no segmento de jeans, camisaria, malha e social. Ela emprega 368 funcionários, com jornada de trabalho de 9 horas (entrada ás 7h, saída ás 17:15h com 1h20min de parada para almoço). As medições de cada setor foram fornecidas pela empresa, resultante do PPRA realizado por um Técnico em Segurança do Trabalho, da empresa contratada para realizar as avaliações: Setor de Corte I - 80,8 a 89,7 $\mathrm{dB}(\mathrm{A})$; Setor de Corte II - 80,8 a 82,2 dB(A); Setor de Costura I - 79,9 a 89,2 dB(A); Setor de Costura II - 79,8 a 88,4 dB(A); Setor de Costura III - 80,5 a 84,4 dB(A); Setor de Costura IV - 79,8 a $84,1 \mathrm{~dB}(\mathrm{~A})$; Setor de Costura Piloto - 81,1 a 86,4 $\mathrm{dB}(\mathrm{A})$; Salão de Bordados - 86,4 a 90,3 dB(A); Setor de Limpadeiras - 80,1 a 82,7 dB(A); Setor de Manutenção I - 82,0 a 89,1 dB(A); Setor de Corrosão/Lixado - 81,9 a 86,1 dB(A); Setor de Caldeira - 81,4 a 82,7 dB(A); Setor de Acabamento I - 76,8 a 79,7 dB(A); Setor de Acabamento II - 80,4 a $89,4 \mathrm{~dB}(\mathrm{~A})$; Setor de Lavagem/Secagem - 80,4 a 87,7 dB(A); Setor de Montagem/Colagem - 79,7 a $82,3 \mathrm{~dB}(\mathrm{~A})$; Setor de Área do USED - 88,4 a 98,2 dB(A); Setor Passadoria - 83,5 a 93,5 dB(A); 


\section{QUESTIONÁRIO}

1. Dados pessoais:

1.1 Idade: anos

1.2 Você fica exposto a ruído fora do ambiente de trabalho? ( ) SIM ( ) NÃO

1.2.1 Cite os lugares:

2. Dados profissionais:

2.1 Há quanto tempo você trabalha nesta empresa?

2.2 Já trabalhou em outra empresa, em que você ficasse exposta ao ruído? ( ) SIM ( ) NÃO

2.2.1 Se positivo: Por quanto tempo?

2.2 Jornada de trabalho atual:

2.2.1 Entrada: horas

2.2.2 Saída: horas

2.2.3 Almoço: hora

3. Em seu trabalho atual, você tem contato com produtos químicos (solventes)?( ) SIM ( ) NÃO

3.1 Faz uso de Equipamento de Proteção Individual? ( ) SIM ( ) NÃO

3.2 Se positivo: Há treinamento para uso? ( ) SIM ( ) NÃO

3.3 Você acha esse treinamento eficiente? ( ) SIM ( ) NÃO

4. Possui algum dos sintomas abaixo:

4.1 Zumbido? ( ) SIM ( ) NÃO

4.2 Dificuldade em entender o que as pessoas falam? ( ) SIM ( ) NÃO

4.3 Insônia? ( ) SIM ( ) NÃO

4.4 Sensação de perda auditiva? ( ) SIM ( ) NÃO

4.4.1 Se positivo: A quanto tempo vem percebendo essa alteração?

4.5 Estresse ou irritação ao final da jornada de trabalho? ( ) SIM ( ) NÃO

4.5.1 Se positivo: A que você atribui esse estresse?

4.6 Sente-se incomodado quando exposto a sons elevados? ( ) SIM ( ) NÃO

Figura 1 - Questionário destinado aos funcionários da empresa participantes da pesquisa

Setor de Serviços Gerais Administrativos - 84,2 a $86,1 \mathrm{~dB}(\mathrm{~A})$. Os demais setores como, Encaixe, Modelagem, Estilismo, Tratamento de Efluentes, Depósito de Produtos Químicos, Almoxarifado, Expedição, Presidência, Recursos Humanos, Faturamento, Compras, Contas a pagar/receber, Vendas, Planejamento e Controle de Produção, Guaritas, Refeitórios, Entretela e Contabilidade, apresentam medições abaixo de $80 \mathrm{~dB}(\mathrm{~A})$, não apresentando risco ruído, entretanto no PPRA está descrito os outros riscos presentes como, calor, poeira e solventes em seus respectivos setores, que não foram listados por não serem objeto deste estudo.

A empresa torna obrigatório o uso de EPl's, realizando treinamento e comprovantes para uso dos mesmos, entretanto, pode-se observar que a maior parte dos trabalhadores não fazem o uso ou sequer sabem das instruções básicas sobre EPl's.
A empresa conta com um médico do trabalho que atua em horários determinados nas dependências da empresa, e arquivamento no local das audiometrias realizadas por clínicas especializadas, escolhidas a cada contrato.

\subsection{Descrição dos setores analisados:}

O setor identificado com maior nível de ruído foi o Setor de Área do USED, onde se realiza a operação de tingimento por meio do processo Used que se descreve por colocar a roupa no local a ser tingida, aplicar a tintura por meio da pistola a ar comprimido, retirar a roupa uma vez tingida, depositá-la em local pré-determinado, e outro serviços afins. As consequências descritas no PPRA para este setor foram: cansaço, irritação, dores de cabeça, redução da audição e etc. Os equipamentos usados neste setor, bem como o ruído produzido por eles, foram listados na Tabela 1. 
Tabela 1 - Descrição dos equipamentos utilizados no setor Used e suas medições

\begin{tabular}{lccc}
\hline Máquinas & $\begin{array}{c}\text { Ruído Pontual } \\
\text { Médio / dB(A) }\end{array}$ & $\begin{array}{c}\text { Ruído Pontual } \\
\text { Máximo / } \\
\text { dB(A) }\end{array}$ & $\begin{array}{c}\text { Dosimetria } \\
\text { Dose Real \% }\end{array}$ \\
\hline Used (cabine) Conjunto de Exaustores & 96,5 & 97,8 & \\
Used (externo) Exaustores e Ar Comprimido - & 96,1 & 98,2 & 353,08 \\
$1^{\circ}$ posto de trabalho & & & \\
$2^{\circ}$ posto de trabalho & 93,2 & 94,1 & \\
$3^{\circ}$ posto de trabalho & 88,4 & 92,7 & \\
\hline
\end{tabular}

O segundo setor analisado foi o Setor de Passadoria, identificado como o segundo setor que apresenta maior risco ruído. A função deste setor é realizar serviços de passagem de roupas, utilizando o processo de prensa à vapor, observando a temperatura e pressão do vapor utilizado e outros serviços afins. As consequências descritas no PPRA foram: cansaço, irritação, dores de cabeça e diminuição da audição. A Tabela 2 lista os equipamentos utilizados neste setor e suas respectivas medições.

Tabela 2 - Descrição dos equipamentos utilizados no setor Passadoria e suas medições

\begin{tabular}{lccc}
\hline Máquinas & $\begin{array}{c}\text { Ruído Pontual } \\
\text { Médio / dB(A) }\end{array}$ & $\begin{array}{c}\text { Ruído Pontual } \\
\text { Máximo / } \\
\mathbf{d B ( A )}\end{array}$ & $\begin{array}{c}\text { Dosimetria } \\
\text { Dose Real \% }\end{array}$ \\
\hline Prensa a Vapor I & 88,1 & 91,2 & \\
Prensa a Vapor II & 88,9 & 92,7 & 143,40 \\
Prensa (virar calça/manequim) & 87,8 & 90,5 & \\
Passagem a ferro & 84,5 & 86,3 & \\
\hline
\end{tabular}

Os dados encontrados nas medições dos equipamentos utilizados nos setores pesquisados (Tabela 1 e 2) foram analisados e confrontados com os limites determinados pela Norma Regulamentadora 15 (NR15) e estão disponíveis na Tabela 3.

Dos 6 sujeitos entrevistados, 3 queixaram-se de estresse ou irritação ao final da jornada de trabalho, atribuindo o ruído como principal fator. Dois sujeitos relataram incomodo quando expostos á sons elevados e nenhum dos entrevistados relataram ter zumbido, insônia ou sensação de perda auditiva/ dificuldade em entender os que as pessoas falam (Figura 2).

$\mathrm{Da}$ amostra analisada, 5 trabalhadores apresentam histórico de normalidade e 1 apresenta perda auditiva. A perda auditiva encontrada foi apresentada no gráfico acima, especificada como perda auditiva ocupacional, esta perda encontra-se estável (Figura 3).

A faixa etária dos entrevistados foi de 28 a 51 anos de idade, sendo que este item não foi usado como critério de participação na pesquisa. $O$ grupo analisado tem de 5 a 24 anos de serviços prestados a empresa, em geral, no mesmo setor. Apenas $16 \%$ dos sujeitos relataram exposição a ruído fora do ambiente de trabalho, justificando como outro emprego, o serviço de garçom em festas por pelo menos três vezes na semana. Dois sujeitos fazem uso de protetor auricular e relatam que o treinamento para o mesmo é eficiente, 1 funcionário relata usar o protetor, porém acha o treinamento ineficaz, enquanto 3 sujeitos não fazem uso do protetor auricular e reclamam do treinamento. 
Tabela 3 - Ruído: Limites de Tolerância (NR-15)

\begin{tabular}{cc}
\hline Nível de Ruído dB(A) & Máxima Exposição Diária Permissível \\
\hline 85 & 8 horas \\
86 & 7 horas \\
87 & 6 horas \\
88 & 5 horas \\
89 & 4 horas e 30 minutos \\
90 & 4 horas \\
91 & 3 horas e 30 minutos \\
92 & 3 horas \\
93 & 2 horas e 40 minutos \\
94 & 2 horas e 15 minutos \\
95 & 2 horas \\
96 & 1 hora e 45 minutos \\
98 & 1 hora e 15 minutos \\
100 & 1 hora \\
102 & 45 minutos \\
104 & 35 minutos \\
105 & 30 minutos \\
106 & 25 minutos \\
108 & 20 minutos \\
110 & 15 minutos \\
112 & 10 minutos \\
114 & 8 minutos \\
115 & 7 minutos
\end{tabular}

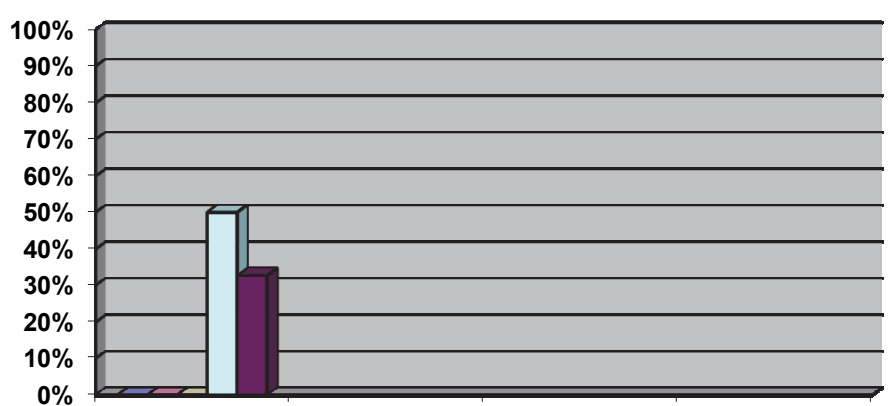

口Zumbido

口Insônia

口Sensação de perda auditiva

DEstresse ou irritação

Encomodo quando exposto a sons elevados

Figura 2 - Gráfico com as respostas obtidas por meio do questionário

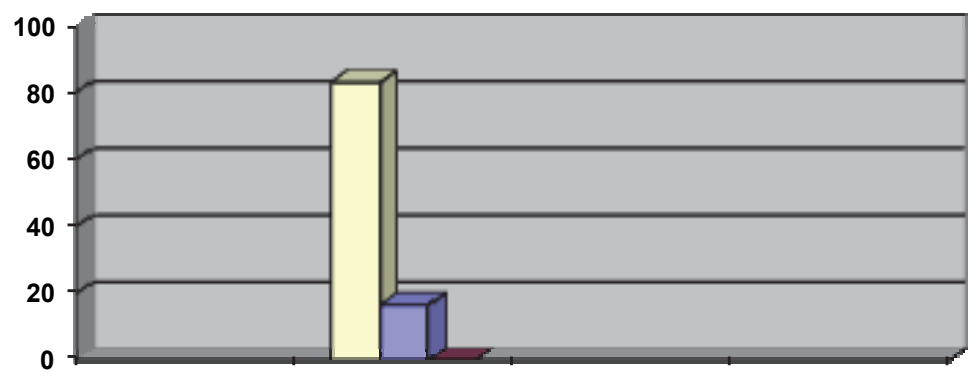

Figura 3 - Gráfico com o resultado da análise das audiometrias avaliadas 


\section{DISCUSSÃO}

Durante a década de 1980, o ruído foi a principal moléstia entre os metalúrgicos e atingia mais de $60 \%$ da categoria ${ }^{7}$, e ainda hoje é classificado como o agente mais frequente de exposição ocupacional 8-11, sendo descrito como uma das principais causas de disacusia neurossensorial em indivíduos adultos ${ }^{12,13}$, geralmente bilateral, irreversível ${ }^{4,8,11,14-16}$, comprometendo a orelha interna e/ ou nervo auditivo ${ }^{17}$, de modo insidioso, produzindo alterações lentamente progressivas e sintomas apenas depois de vários anos ${ }^{18}$.

Essa exposição pode ser muito nociva, completamente inofensiva ou uma medida entre limites. A chave para a questão é a duração da exposição, ou seja, o nível de exposição determina a extensão dos efeitos auditivos do ruído. Todos aqueles que trabalham expostos a ruídos superiores a $85 \mathrm{dBNPS}$ e com exposição prolongada devem ser monitorizados, podendo este ser realizado por meio da audiometria tonal liminar ${ }^{8,19}$.

O maior nível de ruído encontrado nos equipamentos dos setores analisados, gera ruído de 98,2 $\mathrm{dB}(\mathrm{A})$ e considerando a faixa de intensidade ao qual os funcionários são expostos (84,5 a 98,2 dB(A)), verificou-se que o tempo de exposição, em uma jornada de trabalho diária, ultrapassa os limiares permitidos descrito na NR15.

Estatisticamente, estima-se que $15 \%$ da população exposta a ruído constante de $90 \mathrm{~dB}$, oito horas por dia, durante cinco dias por semana e 50 semanas por ano, apresentarão lesão auditiva após dez anos ${ }^{20}$. Este dado torna ainda mais importante a análise dos diversos setores de trabalho, que muitas vezes ultrapassam o tempo de exposição permitido ou o fazem sem a devida proteção. A exposição durante o horário de trabalho a ruídos acima dos limites permitidos dá direito a indenização por danos morais. O entendimento é do Tribunal Regional do Trabalho da 15 ${ }^{\underline{a}}$ Região (Campinas, São Paulo) ${ }^{21}$, como ocorreu no caso da costureira que ganhou indenização da fábrica de roupas em que atuava no setor da lavanderia ${ }^{22}$.

Quando o ruído deixa de ser apenas um agente causador de desconforto no ambiente de trabalho para se tornar um potencial agente nocivo à saúde do trabalhador, ele passa a ter uma abordagem mais específica dentro do campo da Higiene Ocupacional. Destaca-se o Anexo 1 da NR 15 (Tabela 3), que descreve os níveis de ruído presentes no ambiente de trabalho considerados prejudiciais aos trabalhadores.

As alterações auditivas causam um impacto importante na vida das pessoas, podendo levá-las ao isolamento social ${ }^{23}$, pelas dificuldades em participar de conversações, tornando frustrantes qualquer reunião familiar ou evento social ${ }^{24,25}$.

O zumbido é um sintoma que comumente acompanha a perda auditiva ocupacional ${ }^{26}$, podendo proporcionar dificuldades em contextos extralaborais e influencia negativa na qualidade de vida do trabalhador e das pessoas que o cercam ${ }^{27,28}$. Embora nenhum dos candidatos analisados tenha se queixado de zumbido, este sintoma não deve ser desconsiderado, pois para descartá-lo, deve-se antes analisar as queixas de uma população maior de trabalhadores expostos a ruído e com mais de cinco anos de exposição.

Além dos sintomas auditivos frequentes - quais sejam perda auditiva, dificuldade de compreensão de fala, zumbido ${ }^{29,30}$ e intolerância a sons intensos o trabalhador portador de PAIR também apresenta queixas, como cefaléia, tontura e vertigem - devido às importantes alterações que podem ocorrer nas estruturas labirínticas, tornando o uso do protetor auricular importante não somente para proteger a audição, mas também para a preservação da função vestibular ${ }^{31}$ - irritabilidade e problemas digestivos ${ }^{4}$. Também são listados na literatura, sintomas como hipoacusia, plenitude auricular, otalgia, alterações transitórias na pressão arterial, estresse ${ }^{32}$, distúrbios da visão, da memória, do sono e do humor, diretamente relacionadas com o tempo de exposição, com os níveis de pressão sonora (NPS) e com a suscetibilidade individual ${ }^{33,34}$, além da redução da percepção da fala em ambientes ruidosos, televisão, rádio, cinema, teatro, sinais sonoros de alerta, músicas e sons ambientais ${ }^{35} \mathrm{e}$ inabilidade para relaxar ${ }^{36}$.

O estresse foi relatado pelos participantes desta pesquisa, que disseram sentir irritação/estresse ao final da jornada diária de trabalho, mostrando paridade com os sintomas apresentados em outras pesquisas que também relatam ainda a insônia e falta de atenção como consequências da exposição ao ruído ${ }^{15}$.

Os voluntários da pesquisa apresentaram outro sintoma, que também está descrito na literatura como consequência da PAIR: incômodo quando expostos á sons elevados. Nenhum dos entrevistados apresentou queixa de perda auditiva/ dificuldade em entender o que as pessoas falam. A idade dos participantes não foi levada em consideração neste estudo, embora seja pertinente correlacionar com as queixas apresentadas e indagar se a ausência dos sintomas diante a exposição, não seja além do pouco tempo de trabalho (a maioria com apenas cinco anos de serviços neste setor), a jovialidade do indivíduo, bem como de todo o sistema auditivo. 
O diagnóstico de PAIR de origem ocupacional depende dos audiogramas e da comprovação da existência de exposição ao ruído no ambiente de trabalho, considerando-se a intensidade e característica desse agente, assim como o modo e tempo de exposição, as condições gerais de saúde, idade do trabalhador ${ }^{37}$, e o tipo de ruído (contínuo ou intermitente) ${ }^{11}$.

As causas e consequências da PAIR, já estão bastante difundidas a conhecimento geral, embora muitos não sigam as orientações para prevenção desta perda. Entretanto, alguns ambientes de trabalho ainda apresentam escassez de informação, visto que a atual preocupação está voltada para empresas de risco 3 e 4, onde a presença do ruído é notória, não levando em consideração outros setores, que mesmo não sendo notório apresentam riscos à saúde do trabalhador.

Embora apenas um entre os seis trabalhadores analisados apresente PAIR, é taxativo na literatura os efeitos e consequências à audição de pessoas expostas ao ruído. Portanto, tendo em vista que o local apresenta riscos à audição, para uma melhor mensuração dos agravos, novas pesquisas poderão ser realizadas utilizando como critério, trabalhadores com dez anos ou mais de serviços prestados com exposição a ruído. Mesmo que esta pesquisa tenha apresentado índices baixos de reclamações ou perdas, descritas e analisadas nos trabalhadores participantes, não seria preventivo excluir a hipótese de que os trabalhadores apresentados aqui com audição normal, possam apresentar desencadeamento e que uma possível PAIR só seja visível após mais alguns anos de exposição contínua. O ambiente selecionado para análise (dois setores da empresa de confecção) expõe os trabalhadores a limiares acima do limite de tolerância. Diante deste fato, a empresa deve buscar prevenir e solucionar os problemas pertinentes a exposição excessiva, para que o trabalhador deste local não seja afetado.

De acordo com as Normas Regulamentadoras do Ministério do Trabalho, as empresas devem manter um Programa de Prevenção de Riscos Ambientais (PPRA-NR9), no qual os diversos riscos existentes no trabalho devem ser identificados e quantificados para, a partir dessa informação, direcionar as ações do Programa de Controle Médico de Saúde Ocupacional (PCMSO-NR7), que procederá às avaliações de saúde dos trabalhadores ${ }^{4}$.

Em relação ao risco ruído, existe um programa específico para seu gerenciamento, que constam de etapas como Avaliação, Gerenciamento e Controle dos Riscos; Gerenciamento Audiométrico; Treinamento e Programas Educacionais; entre outros. Os objetivos desse programa são: Melhorar a qualidade de vida do trabalhador evitando a surdez e reduzindo os efeitos extra-auditivos causados pela exposição a níveis elevados de ruído e outros agentes de risco para a audição; Diagnosticar precocemente os casos de perdas auditivas ocupacionais, estabelecendo medidas eficazes, preservando a saúde do trabalhador; Adequar a empresa às exigências da lei (Normas Regulamentadoras №s. 7 e 9), para estar em dia com os programas ocupacionais: Perfil Profissiográfico Previdenciário (PPP); Programa de Controle Médico de Saúde Ocupacional (PCMSO); Programa de Prevenção de Riscos Ambientais (PPRA); Programa de Conservação Auditiva (PCA) ${ }^{38}$. O PCA também diminui consideravelmente o risco de acidentes, visto que o risco de sofrer acidentes de trabalho é cerca de duas vezes maior entre trabalhadores expostos ao ruído ${ }^{35}$.

O reflexo da implantação do PCA vai muito além do cumprimento da legislação. Desenvolver programas educativos é um ato de inteligência, pois desenvolve a conscientização, resultando em benefícios diretos tanto para a empresa, quanto para o trabalhador ${ }^{3}$. Para a viabilização deste programa é necessário o envolvimento dos profissionais da área de saúde e segurança, da gerência industrial e de recursos humanos da empresa e, principalmente, dos trabalhadores ${ }^{39}$.

Uma maneira de abrir espaço para que os próprios funcionários expostos participem dos programas, é por meio da Comissão Interna de Prevenção de Acidentes, que foi criada com intuito dos funcionários a utilizarem como instrumento de organização e de melhores condições de trabalho e saúde, pois a análise dos riscos deve contar com a vivência, o conhecimento e a participação dos que realizam o trabalho cotidiano e sofrem seus efeitos ${ }^{7}$. Portanto, conhecendo as dificuldades dos indivíduos diante do ruído poderemos ter condições de implantar um processo educativo dentro de um Programa para Prevenção de Perdas Auditivas ${ }^{23}$.

O PCA trata-se de um conjunto de ações coordenadas que tem por objetivo prevenir ou estabilizar as perdas auditivas ocupacionais. Ações estas, que caracterizam um processo contínuo e dinâmico de implantação de rotinas nas empresas, buscando a redução ou eliminação dos riscos para a audição presentes nos processos produtivos, descrito como um dos objetivos: melhorar a qualidade de vida do trabalhador evitando a surdez e reduzindo os efeitos extra-auditivos causados pela exposição a níveis de pressão sonora elevados e outros agentes de risco para a audição, o que possivelmente diminuiria a discriminação contra esses trabalhadores com perdas auditivas de graus variados, que, quando desempregados, enfrentam a dificuldade de conseguirem novo emprego ${ }^{40}$, iniciando assim 
um processo de desvalorização social e psicológica gerada pelo desemprego.

A avaliação audiométrica dos trabalhadores ainda é a maneira mais efetiva de determinar o sucesso de um PCA. Com a comparação anual dos resultados audiométricos pode-se detectar mudanças ou reforços nas intervenções propostas, encontrando as áreas em que a proteção auditiva (coletiva e/ou individual) tenha falhas ${ }^{38}$. O fonoaudiólogo é um profissional capacitado que fazendo uso dos conhecimentos que possui sobre agentes de risco, o órgão afetado e os exames audiológicos que efetua, pode desenvolver ou enriquecer práticas prevencionistas importantes na promoção da saúde auditiva da população ${ }^{13}$.

Um dos tópicos mais comentados e trabalhados pelos profissionais da fonoaudiologia é o uso e treinamento do Equipamento de Proteção Individual (EPI), que deve ser cuidadosamente considerado, pois a maioria dos trabalhadores não gosta de usá-los e acabam criando certa resistência. A maioria das pessoas expostas a ambientes ruidosos, não sabem os riscos que o ruído traz à saúde; seja por falta de informação, ou por consequência do despreparo da empresa ou por má-fé, quando se tem intenção em ganhar algo da empresa. Neste estudo especificamente, podemos notar que dos seis sujeitos selecionados para pesquisa, apenas três fazem uso de protetor auricular, sendo que um deles relata achar o treinamento ineficaz, o que nos leva a pensar que o protetor pode estar sendo usado de forma incorreta e com isso inutilizar seu efeito. Contudo, mesmo que este dado seja analisado sem indagações, ainda deve-se atender ao fato de que três funcionários - metade da amostra - não faz uso diário do protetor.

Os programas de conservação da audição na indústria são um modo importante de prevenir a perda auditiva. A perda auditiva causada pelo ruído é totalmente incurável hoje, mas também é absolutamente evitável ${ }^{26,40}$.

\section{CONCLUSÃO}

Este ambiente de trabalho apresenta risco ruído, uma vez constatados os níveis de pressão sonora no qual os trabalhadores são expostos durante a jornada de trabalho, bem como a presença de perda auditiva ocupacional, mesmo em menor escala - atribuído ao tempo mínimo de cinco anos de serviços prestados e ao número reduzido de participantes na pesquisa.

\begin{abstract}
Purpose: to get into an underexplored work environment and to identify if this environment might bring hearing losses to the workers. Methods: the environment chosen is a garment factory located in Colatina, Espírito Santo/Brazil. The two noisiest areas of the factory were selected to be analyzed, as well as six employees that have been working there for five years or so. The employees were asked to fill in a questionnaire on the hearing symptoms and then the audiometric tests taken for the last five years were compared. The analyzed areas produce noise from 83,5 to $97,8 \mathrm{~dB}$. Results: from the audiometric tests we could conclude that $83 \%$ of the workers did not have any hearing loss, although $16 \%$ had occupational loss, but this was classified as stable. From the questionnaire we can conclude that $33 \%$ of the workers feel some kind of fatigue when exposed to high level sound for some time, $50 \%$ feel themselves stressed after their work shift, but none of them stated to hear any buzz nor insomnia, nor difficulty hearing other people. Conclusion: this work environment presents some risks to the hearing, once the employees are exposed to sound pressure levels during their work shifts, and the occupational hearing loss is evident although to a lesser extent - considering that the sample employees have been working there for at least five years. Therefore, it is plain to understand the importance of studying a good variety of work environments to identify where prevention programs, like the HLPP (Hearing Loss Prevention Program) should be applied.
\end{abstract}

KEYWORDS: Hearing Loss; Hearing Loss, Noise-Induced; Occupational Risks; Clothing 


\section{REFERÊNCIAS}

1. Botelho CT, Paz APML, Gonçalves AM, Frota S. Estudo comparativo de exames audiométricos de metalúrgicos expostos a ruído e ruído associado a produtos químicos. Rev. Bras. Otorrinolaringol. [periódico na internet]. 2009 [acesso em $2011 \mathrm{Fev}$ 04];75(1):[51-7]. Disponível em: http://www.scielo. com.br

2. Farias VHV, Buriti AKL, Rosa MRD. Ocorrência de perda auditiva induzida pelo ruído em carpinteiros. Rev CEFAC [periódico na internet]. 2012 Mai [acesso em 2012 Jul 20];14(3):413-22. Disponível em: http:// dx.doi.org/10.1590/S1516-18462011005000119

3. Bramatti L, Morata TC, Marques JM. Ações educativas com enfoque positivo em programa de conservação auditiva e sua avaliação. Rev CEFAC [periódico na internet]. 2008 [acesso em 2012 Ago 02];10(3):398-408. Disponível em: http://dx.doi. org/10.1590/S1516-18462008000300016

4. Brasil. Ministério da Saúde. Perda auditiva induzida por ruído (Pair). Secretaria de Atenção à Saúde. Departamento de Ações Programáticas Estratégicas. Brasília: Editora do Ministério da Saúde. 2006.

5. Lima CG. Dossiê Técnico: Prevenção de perdas auditivas ocupacionais causadas por ruídos. Fundação Centro Tecnológico de Minas Gerais CETEC. 2007 [acesso em 2011 Abri 12]. Disponível em: http://www.sbrt.ibict.br

6. Assis SF, Souza JF, Nascimento LC. Diagnóstico dos resíduos sólidos gerados pelas indústrias de confecção de Colatina/ES. Colatina: Centro Federal de Educação Tecnológica do Espírito Santo. 2008 Out 23 [acesso em 18 Out 2012]. Disponível em: http://pse.ifes.edu.br/prppg/pesquisa/jornadas/ jornada_2007_2008/pibiti/engenharias/pibiti\%20 -\%20eng\%20-\%20jonio\%20-\%20sarina\%20-\%20 146\%20147.pdf

7. Mazzeu FJC, Demarco DJ, Kalil L. Segurança e saúde no trabalho. São Paulo: UnitrabalhoFundação Interuniversitária de Estudos e Pesquisas sobre o Trabalho. Brasília - DF: Ministério da Educação. SECAD-Secretraria de Educação Continuada, Alfabetização e Diversidade, (Coleção Cadernos de EJA); 2007 [acesso em 2012 Jan 12]; [aproximadamente 64 p.]. Disponível em: http:// portal.mec.gov.br/secad/arquivos/pdf/10_cd_al.pdf

8. Santos CCS, Juchem LS, Rossi AG. Processamento auditivo de militares expostos a ruído ocupacional. Rev CEFAC [periódico na internet]. 2008 Mar [acesso em 2012 Ago 02];10(1):92-103. Disponível em: http://dx.doi. org/10.1590/S1516-18462008000100013

9. Dias A, Cordeiro R. Fração atribuível de acidentes do trabalho decorrentes da exposição ao ruído ocupacional em cidade do Sudeste do Brasil. Cad Saúde Pública [periódico na internet]. 2007 Jul [acesso em 2012 Jul 23];23(7):1649-55. Disponível em: http://dx.doi.org/10.1590/ S0102-311X2007000700016

10. Holanda WTG, Lima MLC, Figueiroa JN. Adaptação transcultural de um instrumento de avaliação do handicap auditivo para portadores de perda auditiva induzida pelo ruído ocupacional. Ciênc Saúde Coletiva [periódico na internet]. 2011 [acesso em 2012 Ago 02];16(1):755-67. Disponível em: http://dx.doi.org/10.1590/S141381232011000700006

11. Cézar MRV. Atuação do fonoaudiólogo na prevenção da perda auditiva induzida por ruído. CEFAC Recife [monografia na internet]; 2008 [acesso em 2012 Jul 15]; [aproximadamente 42 páginas]. Especialização em Audiologia. Disponível em: http://www.cefac.br/library/teses/6c632bfa6a15 36f760aad180eb36afae.pdf

12. Prudente MF, Costa EA. Exposição ao ruído ocupacional: alterações no exame de emissões otoacústicas. Rev. Bras. Otorrinolaringol. [periódico na internet]. 2006 Jun [acesso em 2012 Jul 20];72(3):362-6. Disponível em: http://dx.doi. org/10.1590/S0034-72992006000300011

13. Morata TC, Zucki F. Promoção da saúde auditiva diante de riscos ambientais: uma reflexão da atuação e da produção científica na área. In: Morata TC, Zucki F. Caminhos para a saúde auditiva: ambiental - ocupacional. São Paulo: Plexus Editora; 2005. p.11-27.

14. Teles RM, Medeiros MPH. Perfil audiométrico de trabalhadores do distrito industrial de Maracanaú - CE. Rev. Soc. Bras. Fonoaudiol. [periódico na internet]. 2007 [acesso em 2012 Jul 20];12(3):233-9. Disponível em: http://www.scielo.br/pdf/rsbf/v12n3/ a11v12n3.pdf

15. Faria CAR, Suzuki FA. Avaliação dos limiares auditivos com e sem equipamento de proteção individual. Rev. Bras. Otorrinolaringol. [periódico na internet]. 2008 [acesso em 2012 Jul 20];74(3):417-22. Disponível em: http://dx.doi. org/10.1590/S0034-72992008000300017

16. Riveiro VFM. Ruído e suas consequências para o adoecimento: uma revisão integrativa de literatura. Universidade Federal do Rio Grande do Sul [monografia na internet]; 2010 [acesso em 2012 Ago 02].[aproximadamente 45 páginas]. Disponível em:http://www.lume.ufrgs.br/bitstream/ handle/10183/28226/000770079.pdf?sequence=1

17. Fernandes LCBC, Gil D, Maria SLS, Azevedo MF. Potencial evocado auditivo de tronco encefálico por via óssea em indivíduos com perda auditiva sensorioneural. Rev CEFAC [periódico na internet]. 2012 Mar [acesso em 2012 Ago 02],pp.0-0. 
Disponível em: http://dx.doi.org/10.1590/S151618462012005000018

18. Pereira RT, Minette LJ, Magalhães BL, Abrantes BA, Silva EP, Souza AP. Avaliação ergonômica dos fatores ambientais de uma indústria de confecção na zona da mata mineira. UFV: III SAEPRO; 2007 [acesso em 2012 Jan 13]. Disponível em: http:// www.saepro.ufv.br/Image/artigos/SA04.pdf

19. Rocha EB, Azevedo MF, Filho JAX. Estudo da audição de crianças de gestantes expostas ao ruído ocupacional: avaliação por emissões otoacústicas - produto de distorção. Rev. Bras. Otorrinolaringol. [periódico na internet]. 2007 Jun [acesso em 2012 Jul 20];73(3):359-69. Disponível em: http://dx.doi. org/10.1590/S0034-72992007000300011

20. Rodrigues MAG, Dezan AA, Marchiori LLM. Eficácia da escolha do protetor auditivo pequeno, médio e grande em programa de conservação auditiva. Rev CEFAC [periódico na internet]. 2006 Dez [acesso em 2012 Jul 20];8(4):543-7. Disponível em: http://dx.doi.org/10.1590/S151618462006000400016

21. Costa JL. Perda auditiva por excesso de ruído no trabalho gera dano moral. Revista Consultor Jurídico. [base de dados na internet]. 2005 Jun 17 [acesso em 2012 Jul 20]. [7 páginas]. Disponível em: $\quad$ http://www.conjur.com.br/2005-jun-17/ perda_auditiva_ruido_trabalho_gera_dano_moral

22. Revista Consultor Jurídico. [base de dados na internet]. 2011 Mar 1 [acesso em 2012 Jan 13]. Costureira deve ser indenizada por perda auditiva; [1 página.]. c2011. Disponível em: http:// www.conjur.com.br/2011-mar-01/costureiraindenizada-perda-auditiva-decide-trt-rs

23. Bramatti L, Morata TC, Marques JM, Martini UG. Versão e adaptação para o português brasileiro do questionário: crenças e atitudes sobre prevenção de perda auditiva. Rev CEFAC [periódico na internet]. $2012 \mathrm{Fev}$ [acesso em 2012 Ago 02]; 14(1):65-78. Disponível em: http://dx.doi. org/10.1590/S1516-18462011005000082

24. Signorini TA. Deficiência auditiva do idoso e sua implicação na comunicação. In: Gonçalves CGO, Mota PHM, Marques JM. Ruído e idade: análise da influência na audição em indivíduos com 50 - 70 anos. Pró-Fono R. Atual. Cient. [periódico na Internet]. 2009 Mar [acesso $2011 \mathrm{Jul}$ 02];21(1):57-62. Disponível em: http://www.scielo. br/scielo.phpscript=sci_arttet\&pid=SOQO45687200 9000100010\&lng=pt

25. Mondelli MFCG, Rocha AB. Correlação entre os achados audiológicos e incômodo com zumbido. Arquivos Int. Otorrinolaringol. (Impr.) [periódico na internet]. 2011 Jun [acesso em 2012 Ago 02];15(2):172-80. Disponível em: http://dx.doi. org/10.1590/S1809-48722011000200009
26. Pfeiffer M, Rocha RLO, Oliveira FR, Frota S. Intercorrência audiológica em músicas após um show de rock. Rev CEFAC [periódico na Internet]. 2007 [acesso em 2012 Jul 23];9(3):423-9. Disponível em: http://redalyc.uaemex.mx/src/inicio/ArtPdfRed. jsp?iCve $=169313371017$

27. Dias A, Cordeiro R. Interação entre grau de perda auditiva e o incômodo com zumbidos em trabalhadores com história de exposição ao ruído. Rev. Bras. Otorrinolaringol. [periódico na Internet]. 2008 Dez [acesso em 2011 Jul 01];74(6): 876-83. Disponível em: http://www.scielo.br/scielo. php?script=sci_arttext\&pid=S00347299200800060 0010\&lng=pt

28. Ganime JF, Silva LA, Robazzi MLCC, Sauzo SV, Faleiro SA. El ruido como riesgo laboral: una revisión de la literatura. Revista eletronica de enfermaria [periódico na internet]. 2010 [acesso em 2012 Jul 17]; 19 [aproximadamente 10 p]. Disponível em: http://scielo.isciii.es/pdf/eg/n19/pt_revision1.pdf 29. National Institute for Occupational Safety and Health. Preventing occupational hearing loss: a practical guide. In: Bramatti L, MorataTC, Marques JM. Ações educativas com enfoque positivo em programa de conservação auditiva e sua avaliação. Rev CEFAC [periódico na internet]. 2008 [acesso em 2012 Jul 20];10(3): 398-408. Disponível em: http:// dx.doi.org/10.1590/S1516-18462008000300016

30. Steinmetz LG, Zeigelboim BS, Lacerda AB, Morata TC, Marques JM. Características do zumbido em trabalhadores expostos a ruído. Rev. Bras. Otorrinolaringol. [periódico na internet]. 2009 Fev [acesso em 2012 Jul 20];75(1):7-14. Disponível em: http://dx.doi.org/10.1590/S003472992009000100002

31. Teixeira CS, Körbes D, Rossi AG. Ruído e equilíbrio: aplicação da posturografia dinâmica em indústria gráfica. Rev CEFAC [periódico na internet]. 2011 Fev [acesso em 2012 Ago 02];13(1):92101. Disponível em: http://dx.doi.org/10.1590/ S1516-18462010005000016

32. Boger ME, Branco AB, Ottoni ÁC. A influência do espectro de ruído na prevalência de Perda Auditiva Induzida por Ruído em trabalhadores. Braz. j. otorhinolaryngol. (Impr.) [periódico na internet]. 2009 Jun [acesso em 2012 Ago 02];75(3):328-34. Disponível em: http://dx.doi.org/10.1590/ S1808-86942009000300003

33. Ribeiro BL, Machado AA, BackDC. Perda auditiva induzida por níveis de pressão sonora elevados na indústria. CEFAC [monografia na internet]. 2009 [acesso em 2011 Jul 2];[aproximadamente 12 p.]. Disponível em: http://www.cefac.br/library/artigos/4 994382af80a4b40a3fdd9dea3e405e9.pdf

34. Ribeiro AMD, Câmara VM. Perda auditiva neurossensorial por exposição continuada a níveis 
elevados de pressão sonora em trabalhadores de manutenção de aeronaves de asas rotativas. Cad. Saúde Pública [periódico na Internet]. 2006 [acesso em 2012 Jul 20];22(6):1217-24. Disponível em: http://www.scielo.br/scielo

35. Lopes AC, Almeida AC, Mello ADP, Otubo KA, Lauris JRP, Santos CC, et al. Characterization of the Audiologic Thresholds in Workers of Funeral Urns. Int Arch Otorhinolaryngol. [periódico na internet]. 2009 [acesso em 2012 Ago 02];13(3):244-51. Disponível em: http://www.arquivosdeorl.org.br/ conteudo/pdfForl/13-03-02.pdf

36. Weber SR, Périco E. Zumbido no trabalhador exposto ao ruído. Rev. Soc. Bras. Fonoaudiol. [periódico na internet]; 2011 Dez [acesso em 2012 Ago 02]. 16(4): 459-65. Disponível em: http://dx.doi. org/10.1590/S1516-80342011000400016

37. Guida HL, Morini RG, Cardoso ACV. Avaliação audiológica em trabalhadores expostos a ruído e praguicida. Braz. j. otorhinolaryngol. (Impr.) [periódico na internet]. 2010 Ago [acesso em 2012 Ago 02];76(4):423-7. Disponível em: http:// dx.doi.org/10.1590/S1808-86942010000400003
38. Bernardi e Saldanha. 2003. In: Lima CG. Dossiê Técnico: Prevenção de perdas auditivas ocupacionais causadas por ruídos. Fundação Centro Tecnológico de Minas Gerais - CETEC. 2007 [acesso em 2011 Abri 12]. Disponível em: http://www.sbrt.ibict.br

39. Ministério da Previdência e Assistência Social. OS/INSS no 608, 05/08/1998 - Aprova Norma Técnica sobre Perda Auditiva Neurossensorial por Exposição Continuada a Níveis Elevados de Pressão Sonora de Origem Ocupacional. In: Souza MHP, Mercuri AAS, Azevedo MF, Bernardi APA. Análise de emissões otoacústicas produtos de distorção em trabalhadores de uma indústria metalúrgica na cidade de Birigui. Rev CEFAC. [periódico na internet]. 2010 [acesso em 2012 Jul 20]. Disponível em: http://www.cefac.br/library/ artigos/f18097d018dd48c1f9743c47e7835710.pdf 40. Ogido R, Costa EA, Machado HC. Prevalência de sintomas auditivos e vestibulares em trabalhadores expostos a ruído ocupacional. Rev. Saúde Pública [periódico na internet]. 2009 [acesso em 2012 Jul 20];43(2):377-80. Disponível em: http://www.scielo. $\mathrm{br} / \mathrm{pdf} / \mathrm{rsp} / \mathrm{v} 43 \mathrm{n} 2 / 7239 . \mathrm{pdf}$

http://dx.doi.org/10.1590/1982-021620149912

Recebido em: 20/04/2012

Aceito em: 10/12/2012

Endereço para correspondência:

Daniela Dalapicula Barcelos

Rua Dulce Brito Espíndula, 21, Ed. Praia de

Capuba, apto 601

Jardim Camburi - Vitória - ES

CEP: 29090-340

E-mail: danidalapicula@yahoo.com.br 